duas sessőes de posters muito participadas que contribuiram para a troca de experiências entre os vários participantes. Na sessão de encerramento foram atribuídos dois prémios: o prémio para a melhor fotografia, atribuído entre as contribuições dos alunos do $2 .^{\circ}$ ano do Mestrado em Técnicas de Caracterização e Análise Química, e o prémio para a melhor comunicação em painel. Este evento contou com o apoio da Sociedade Portuguesa de Química e da Universidade do Minho e com o patrocínio de algumas empresas que gentilmente se associaram a esta organização.

Susana Costa (spc@quimica.uminho.pt) Comissão Organizadora do II ETCAQ na Universidade do Minho

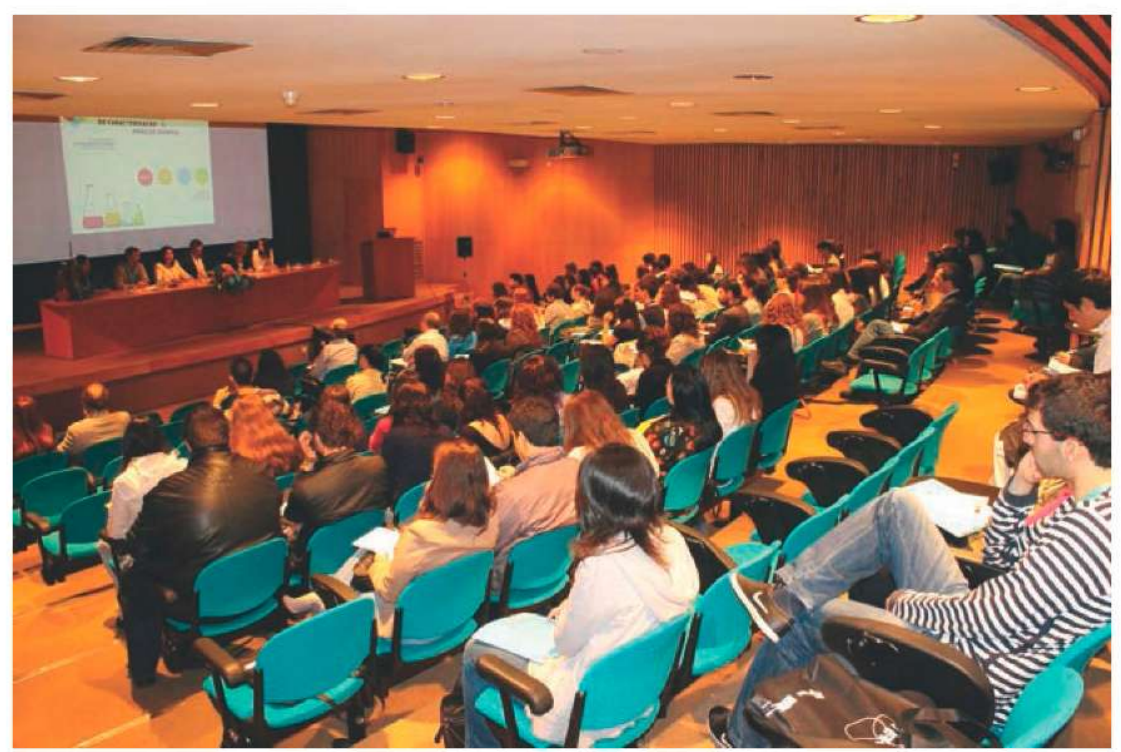

Perspetiva do Anfiteatro na sessão de abertura do II ETCAQ

\title{
A Química no Mundo - Uma Retrospetiva sobre as Primeiras Jornadas de Química da FCUP
}

final do passado mês de maio foi de celebração no Departamento de Química e Bioquímica (DQB) da Faculdade de Ciências da Universidade do Porto (FCUP). Nos dias 23 e 24 desse mês decorreram as Primeiras Jornadas da Química da FCUP (Figura 1), um evento que teve o apoio da Sociedade Portuguesa de Química. Subordinadas ao tema aglutinante "A Química no Mundo", estas jornadas trouxeram à atenção os vários domínios em que a Química surge como área científica central no conhecimento.

Nas palavras de Catarina Costa, aluna da licenciatura em Química e porta-voz da comissão organizadora do evento, "Quem frequenta ou frequentou a licenciatura em Química certamente já se interrogou qual é o papel da Química na sociedade. $\mathrm{Na}$ verdade, a maioria das pessoas não sabe realmente o que é a Química, logo torna-se imperativo tentar mostrar esta ciência, falar do que se faz ou se poderá fazer com ela, o que se aprende e a sua importância no mundo. Surgiu assim a ideia de promover um encontro entre as várias áreas da Química, num evento nunca antes realizado na Faculdade de Ciências da Universidade do Porto - as Jornadas da Química". Este encontro contou ainda com a colaboração de representantes de empresas diretamente relacionadas com a Química e com especialistas académicos das mais variadas áreas da Química.

A organização deste evento envolveu mais de uma dezena de estudantes de licenciatura e mestrado em Química. Um dos organizadores, Paul Costa, mencionou a importância deste tipo de eventos na promoção da Química no ambiente académico e até fora dele. Referiu também algumas dificuldades na produção de um evento desta magnitude, mas não deixou de elogiar os patrocinadores e todos os que apoiaram incansavelmente a organização destas jornadas.

A sessão de abertura do evento contou com a participação do Prof. Dr. António Teixeira Marques, Vice-Reitor da Comunicação, Imagem e Relações Internacionais da UP, do Prof. Dr. António Fernando da Silva, Diretor da FCUP, da Profa. Dra. Maria João Ramos, Professora Catedrática na FCUP e do Prof. Dr. Alexandre MagaIhães, Diretor da licenciatura em Química da FCUP. Todos foram unânimes em louvar o esforço dos organizadores do evento por todo o trabalho e tempo investidos na criação, estruturação e implementação de um projeto desta envergadura. Seguidamente, a assistência foi presenteada com uma belíssima palestra do Prof. Dr. José

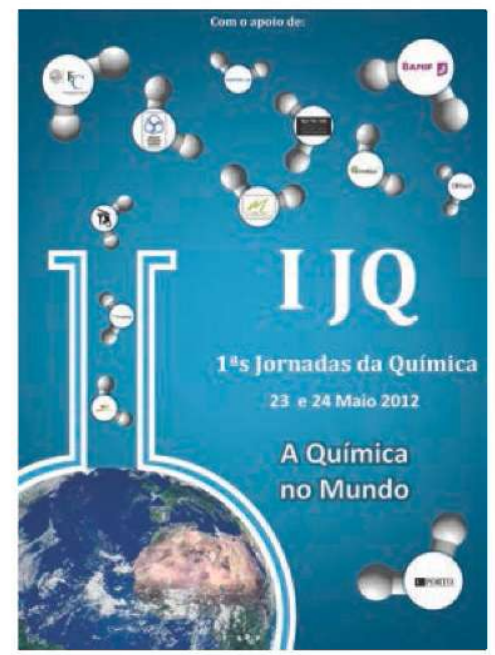

Figura 1 - Cartaz das Primeiras Jornadas de Química da FCUP

Veiga Simão, ex-Ministro da Educação e protagonista de uma reforma profunda no ensino universitário. $A$ palestra com o tema "A reforma "Veiga Simão" - 40 anos de Licenciatura em Química" trouxe à atenção a história do ensino académico das ciências físico-químicas e refletiu sobre as novas tendências de ensino académico em Portugal. Foi extremamente enriquecedor analisar como a lecionação académica da Química evoluiu nacionalmente. De seguida, o Dr. Nuno Palma, Investigador da empresa Bial abordou o tema " $A$ indústria Farmacêutica - Bial", onde o autor refletiu sobre a importância da Química Teórica e Computacional como meio de 
facilitar a investigação na área da síntese de novas moléculas direcionadas a alvos farmacológicos específicos.

Depois de uma pausa, nada melhor para recomeçar o ciclo de palestras do que "Um cheirinho de Química Orgânica", palestra protagonizada pelo já mítico químico orgânico português Prof. Dr. Carlos Corrêa. Sempre com a boa-disposição que o caracteriza, o professor focou a sua atenção, entre muitos assuntos, nos radicais livres, na autoxidação e nos antioxidantes - mais uma bela aula de Química Orgânica como o professor sempre nos habituou. $\mathrm{Na}$ continuação da série de palestras houve a oportunidade de escutar a Profa. Dra. Ana Cristina Freire, Professora Associada da FCUP, com o interessante e contemporâneo tema "Contribuição da Química para a Nanotecnologia". Nesta apresentação toda a assistência ficou muito satisfeita com uma série de exemplos de preparação de nanomateriais com funcionalidades e propriedades específicas e a sua aplicação no fabrico de têxteis funcionais. $O$ primeiro dia das jornadas terminou com a palestra do Prof. Dr. Fernando Pereira, Professor Associado da Faculdade de Engenharia da UP. Esta palestra, "Materiais de Carbono em tecnologias ambientais o papel da Química Superficial", versou sobre a problemática da química superficial dos materiais de carbono e forneceu exemplos da utilização desses materiais em aplicações ambientais como adsorventes de compostos orgânicos em soluções aquosas e como catalisadores na oxidação de poluentes orgânicos.

Volvido o primeiro dia de jornadas, chegou o tempo de abrir o segundo dia com a colaboração do Prof. Dr. José António Rodrigues, Professor Auxiliar da FCUP, que destacou "O papel da Química Analítica na Qualidade e Segurança Alimentar". Esta palestra abordou diversas generalidades sobre a Química Analítica, mas também respondeu com argumentação sólida à pergunta: É a Química Analítica realmente importante no contexto da indústria alimentar? Depois desta abordagem analítica à Química, havia chegado o momento de voltar a atenção da assistência para a Química Física na palestra do Prof. Dr. Eduardo Figueira Marques, Professor Auxiliar da FCUP. O investigador mostrou a "Química-Física nas interfaces e auto-organização molecular", destacando também o caráter central e a importância da interdisciplinaridade em Química.

Por fim, a primeira Grande Conferência com o tema "Estou na Licenciatura em Química, que caminho escolher?". Esta conferência/debate contou com a moderação do Prof. Dr. João Paiva, Professor Auxiliar da FCUP, e com a participação da Dra. Ana Cristina Freire, da Dra. Maria João Ramos, do Prof. Dr. José Ferreira Gomes, Professor Catedrático da FCUP, da aluna do mestrado em Química Cármen Santos e da aluna da licenciatura em Química com minor em Física Isabel Saúde (Figura 2). Nesta Grande Conferência houve a oportunidade de refletir sobre as principais problemáticas associadas à licenciatura em Química e discutiu-se com alguma profundidade os diferentes percursos que cada minor da licenciatura oferece. Houve também a oportunidade de ficar a conhecer melhor os constrangimentos sentidos pelos docentes na adequação dos planos de estudos às perspetivas de um licenciado em Química. O estimulante debate fechou a manhã do último dia das jornadas. Restavam apenas três palestras e mais uma Grande Conferência.
O início dessa tarde ficou ao cargo do Prof. Dr. Gabriel Monteiro, Investigador no Institute for Biotechnology and Bioengineering. Esta palestra versou sobre as temáticas da "(Bio)Química - A Química aliada à Biologia", evocando as diversas utilizações das biomoléculas e o contexto vanguardista desta área da Química. O Prof. Dr. Joaquim Esteves, Professor Associado da FCUP, continuou a tarde muito bem passada com o tema "Química Ambiental: A Química na Interface". Nesta sua participação, o investigador trouxe à atenção, de uma forma descontraída e repleta de humor, a importância dos químicos no ambiente e analisou a Química Ambiental que, por estar em constante contacto com outras áreas do conhecimento, pode ser denominada de "Química na Interface". Seguidamente, a Profa. Dra. Fernanda Borges, Professora Associada da FCUP, presenteou a assistência com um tema de grande interesse: "Química sob Investigação - A Química aplicada às Ciências Forenses". Nesta palestra todos ficamos a conhecer melhor o trabalho que tem sido feito no Departamento na área da Química Forense.

Por fim, havia chegado o tempo para a última Grande Conferência, desta feita subordinada ao tema "Sou licenciado, o que esperam de mim?". Esta conferência, direcionada a alunos prestes a concluírem a licenciatura ou mestrado, contou com a presença de empresas, investigadores e ex-alunos que partilharam a sua experiência no mercado de trabalho. Esta conferência/debate teve a moderação do Presidente da Direção da Associação de Estudantes da FCUP, Ivo Reis. Além disso, esta conferência contou com a colaboração do Eng. Pedro Marques, representante da empresa Tintas

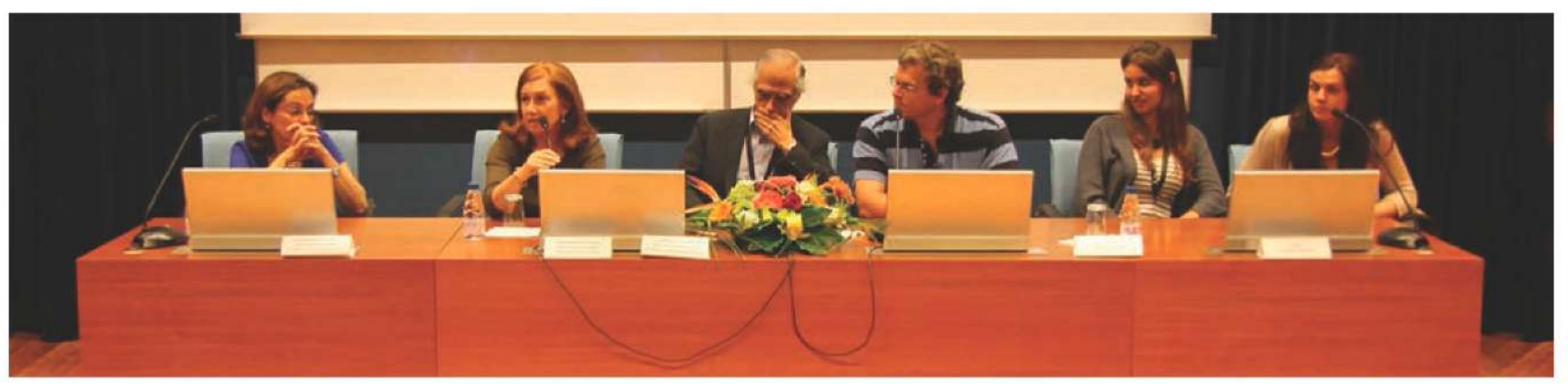

Figura 2 - Os elementos da mesa na Grande Conferência "Estou na Licenciatura em Química, que caminho escolher?" 
Conquistador, com a consultora de percursos profissionais da Cidade das Profissões, Catarina Reis, bem como com o investigador Fábio Rizzo e com - Colaborador da Casa das Ciências, Daniel Ribeiro. Foi agradável notar o interesse dos alunos de licenciatura e mestrado em conhecerem diferentes formas de enriquecer a sua formação académica e profissional.

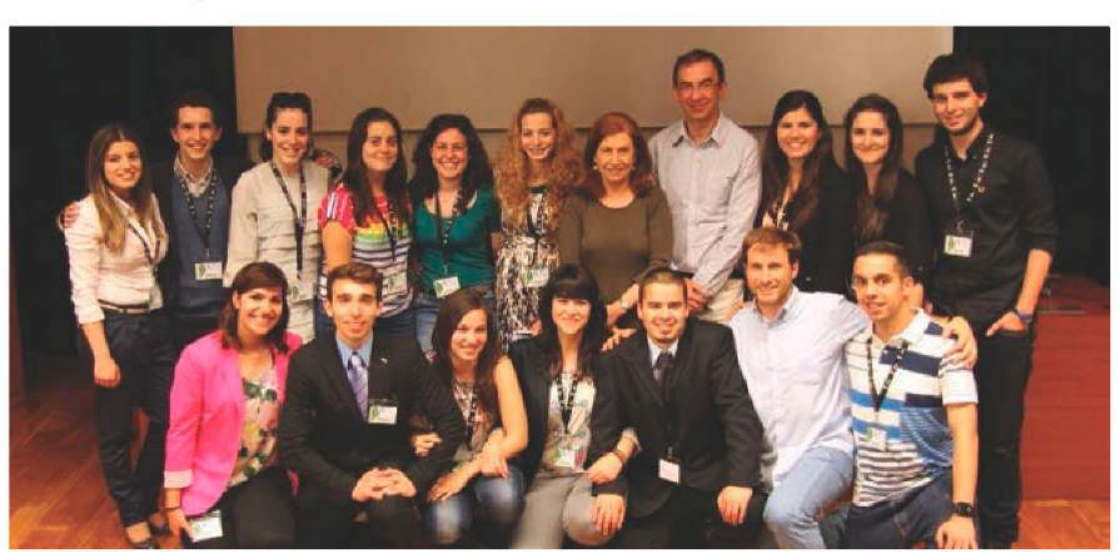

Figura 3 - A comissão organizadora das Jornadas de Química da FCUP
Todos ficaram extremamente satisfeitos com estas jornadas e com o interesse demonstrado. Foi gratificante ver o esforço da comissão organizadora (Figura 3) dar os seus frutos. A divulgação da Química desempenha um papel vital na promoção do futuro da investigação e trabalho químico em Portugal. Estas jornadas tiveram o condão de contagiar todos de um es-

pírito de dedicação, empenho e motivação que geram mais e melhores trabalhadores no futuro. Que eventos como estes possam sempre ser apoiados com o objetivo de aumentar a paixão pela Química que todos nós sentimos. E que estas sejam as primeiras de muitas jornadas de química para todos.

Poderá obter mais informações acerca das jornadas em www. facebook. com/lJornadasQuimicaFCUP, www2. fc. up.pt/jquimica2012 ou através do e-mail jquimica2012@gmail.com.

\section{Daniel Ribeiro}

(danieltiago.ribeiro@gmail.com) Licenciado em Química e Mestre em Ensino da Física e da Química pela FCUP

Paulo Ferreira

(paulo_jferreira@live.com.pt) Licenciado em Química e Mestrando em Química pela FCUP

\section{Ação Integrada Luso-Espanhola Reúne Mais de 60 Investigadores na FFUL}

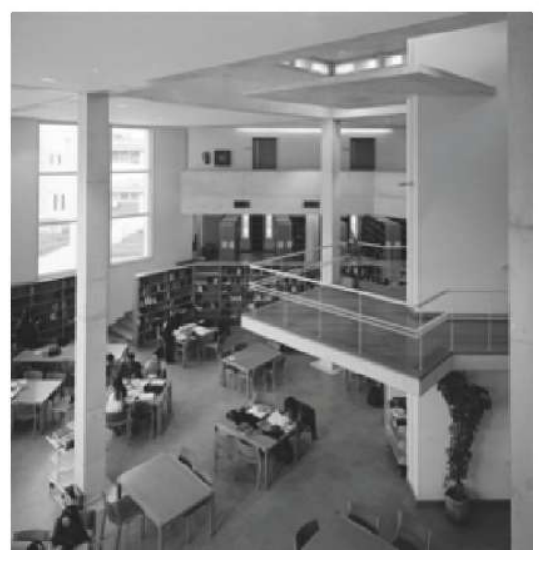

No dia 1 de junho realizou-se, na Faculdade de Farmácia da Universidade de Lisboa (FFUL), um workshop de
Química Orgânica e Medicinal organizado pela investigadora Maria M. M. Santos do Research Institute for Medicines and Pharmaceutical Sciences (iMed.UL), da Faculdade de Farmácia da Universidade de Lisboa, e por Mercedes Amat, investigadora da Faculdade de Farmácia da Universidade de Barcelona. O encontro reuniu cerca de 60 investigadores da Universidade de Lisboa (UL), Universidade Técnica de Lisboa (UTL), Universidade Nova de Lisboa (UNL) e Universidade de Barcelona, tendo sido apresentados temas muito inovadores de diferentes áreas da química. Durante a manhã foram apresentadas comunicações relacionadas com novas estratégias para a síntese enantioselectiva de produtos naturais, utilização de organocatalisadores em solventes não tóxicos, assim como síntese de potenciais antagonistas do receptor de NMDA e síntese de inibidores de HIV-1. Durante a tarde abordaram-se temas relacionados com a síntese de novos antimaláricos, com o potencial dos sedimentos oceânicos como fonte de compostos bioativos, bem como a resolução cinética enzimática de álcoois secundários.

Maria M. M. Santos (mariasantos@ff.ul.pt) Comissão Organizadora

\section{Grupo de Químicos Jovens - Nova Direção}

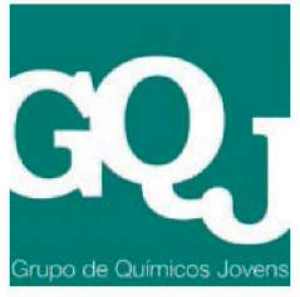

Desde 2009, e durante dois anos, a direção do Grupo de Químicos Jovens (GQJ) foi assegurada pela Mariana Sardo, Sérgio Santos e Vânia Calisto, da Universidade de Aveiro. Em maio último, na sequência da realização do $3^{\text {rd }}$ Portuguese Young Chemists Meeting (3PYCheM), a direção do GQJ passou para o Porto.
É com muito agrado que os membros da atual direção, Inês M. Valente, Luís M. Gonçalves e Marisa Rocha, recebem esta missão até 2014.

Nesta fase inicial à frente do GQJ foi feita uma reformulação da página do 